\title{
Faktor Kesuksesan Sistem E-Office Rumah Sakit dalam Upaya Meningkatkan Kepuasan Pengguna
}

\author{
http://dx.doi.org/10.28932/jutisi.v6i2.2559
}

\author{
Ari Cahaya Puspitaningrum ${ }^{\bowtie \# 1}$ \\ STIE Perbanas \\ Jalan Nginden Semolo, Surabaya \\ 1ari.cahayadperbanas.ac.id
}

\begin{abstract}
Nowadays, hospital industries are aware of the importance of technological innovation that needs to be managed properly to drive business continuity and success in the future. The development of technological innovation in hospital industries has increased over time. This happens because of the desire to compete with each other continuously by utilizing technological innovation. This study has observed the existing information systems in the hospital, where the business process of the information system focuses on the hospital's internal correspondence process. This information system is called an e-office which is intended for the National Center General Hospital (RSUPN) Dr. Cipto Mangunkusumo. This study aims to determine what factors influence the successful implementation of the e-office system as seen from the evaluation of user satisfaction. Besides that, this study observed what efforts were made by the PT. Vidya Sentra Utama (Sevima) to create a successful and usable e-office system, where e-office is a large and complex system that includes more than 77 divisions with different business processes. Data collection methods used were interviews, observation, and document analysis. This study contributes to Sevima's knowledge of what factors of success need to be measured to determine user satisfaction and what needs to be done by Sevima's agile team to developing information systems and provide references for further research to evaluate an information system.
\end{abstract}

Keywords — E-Office; Hospital Information System; Information System Success; User Satisfaction.

\section{Pendahuluan}

Selama beberapa tahun terakhir, sebagian besar industri rumah sakit telah melakukan identifikasi terkait faktor faktor penting di rumah sakit yang apabila dikelola dengan baik akan mendorong keberlangsungan bisnis dan kesuksesan di masa yang akan datang [1]. Hal ini dapat dilihat dari peningkatan inovasi teknologi yang diterapkan oleh rumah sakit sebagai salah satu faktor yang sangat penting. Perkembangan inovasi teknologi di industri rumah sakit semakin meningkat seiring berjalannya waktu [1]. Rumah sakit memiliki keinginan untuk bersaing secara terus menerus dengan memanfaatkan inovasi teknologi [2] Tujuan dari penerapan inovasi teknologi ini adalah untuk meningkatkan layanan baik kepada penyedia layanan medis dan penerima layanan [3]. Selain itu, inovasi teknologi juga mampu meningkatkan performa kinerja internal.

Penelitian sebelumnya telah mengamati pemanfaatan inovasi teknologi pada rumah sakit yaitu berupa sistem informasi. Adapun sistem informasi yang telah digunakan pada objek penelitian sebelumnya yaitu hospital information system (HIS), e-health, m-health, dan clinical information systems. Sistem informasi tersebut menyediakan fitur - fitur yang dapat digunakan untuk mengelola seluruh aspek operasional rumah sakit misalnya aktivitas klinis, administratif, dan keuangan [4]. Selain itu, sistem informasi tersebut juga dapat mendukung kemudahan staf dalam melakukan pekerjaan, dapat mengurangi kesalahan medis, mengurangi biaya operasional, meningkatkan kualitas kesehatan pasien, dan meningkatkan keselamatan pasien [1][5][6].

Mengembangkan sistem informasi di industri rumah sakit bukanlah hal yang mudah [4], perlu memperhatikan beberapa faktor, yaitu faktor pengguna, biaya, dan waktu dalam proses pengembangannya [7]. Menurut Alipour et al., [4] dan Kimiafar [8], sebuah sistem informasi dapat dikatakan sukses apabila sesuai dengan tujuan dan dapat memenuhi kebutuhan bisnis rumah sakit. Selain itu, dalam upaya meningkatkan kesuksesan dari sistem informasi perlu dilakukan evaluasi atau pengukuran terhadap kegunaan sistem informasi tersebut untuk mengetahui tingkat kepuasan penggunaan dari faktor apa saja pengguna merasa 
puas terhadap kegunaan sistem informasi tersebut [2][4][6][9][10].

Penelitian ini mengambil topik tentang evaluasi penggunaan sistem $e$-office. E-office merupakan sistem surat menyurat internal yang dimiliki oleh Rumah Sakit Umum Pusat Nasional Dr. Cipto Mangunkusumo. Sistem informasi ini dikembangkan oleh pihak ketiga, yaitu PT. Vidya Sentra Utama (Sevima). E-office dikembangkan oleh tim Agile dari PT. Sevima, yang mana proses pengembangannya mengacu pada aturan Kementerian Kesehatan Republik Indonesia. Sistem ini memberikan kemudahan kepada pihak RSUPN Dr. Cipto Mangunkusumo dalam menyajikan berbagai informasi terkait surat, berkas dokumen, dan disposisi yang valid, akurat, actual, cepat dan tepat secara online [11]. Berdasarkan hasil wawancara dengan pihak Sevima, dapat disimpulkan bahwa e-office ini merupakan sistem yang kompleks yang mencakup proses bisnis lebih dari 77 divisi yang ada di RSUPN Dr. Cipto Mangunkusumo.

Tim Agile Sevima melakukan evaluasi secara terus menerus terhadap e-office yang dilakukan setiap tahun. Evaluasi dilakukan melalui kuesioner yang disebarkan ke seluruh divisi yang memanfaatkan e-office. Kuesioner tersebut mencakup faktor - faktor yang dijadikan ukuran kesuksesan dan kegagalan dari sistem e-office. Hasil evaluasi akan digunakan oleh pihak Sevima untuk terus meningkatkan pelayanan kepada RSUPN Dr. Cipto Mangunkusumo dengan menjawab seluruh pertanyaan melalui chating, menangani komplain, dan memperbaiki fitur - fitur yang sulit untuk dioperasikan oleh divisi.

Penelitian ini dilatarbelakangi oleh adanya permasalahan yang dihadapi oleh PT Sevima dalam mengembangkan sistem e-office milik RSUPN Dr. Cipto Mangunkusumo. PT. Sevima tidak hanya membangun sistem e-office tersebut, namun juga melakukan maintenance, menangani komplain, dan melakukan perubahan pada fitur - fitur sesuai kebutuhan RSUPN Dr. Cipto Mangunkusumo. Kebutuhan rumah sakit tersebut terus bertambah dan tidak hanya dari satu divisi saja, namun dari 77 divisi. Hal tersebut menuntut Sevima untuk melakukan evaluasi secara berkala sehingga mengetahui kebutuhan rumah sakit dan apa saja yang perlu diperbaiki dan ditingkatkan pada sistem e-office. Beberapa penelitian terdahulu telah menemukan faktor - faktor yang mempengaruhi kepuasan pengguna terhadap penggunaan sistem informasi. Namun, penelitian tersebut belum cukup mendetilkan upaya apa saja yang perlu dilakukan oleh organisasi dalam meningkatkan kinerja dan kualitas dari sistem informasi terkait. Selain itu, belum banyak yang menghasilkan suatu rekomendasi untuk kesuksesan sistem informasi dengan menggunakan 2 data, yaitu data dari lapangan (praktisi) dengan data dari penelitian sebelumnya (akademik).

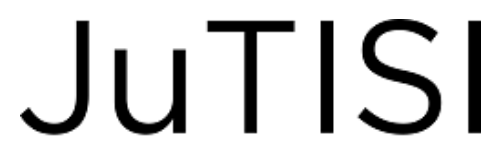

Berdasarkan hal tersebut, maka penelitian ini bertujuan untuk menghasilkan faktor - faktor apa saja yang perlu ditambahkan oleh Sevima dalam mengevaluasi kepuasan pengguna sistem e-office berdasarkan hasil pengumpulan data dan penelitian sebelumnya. Selain itu, juga menghasilkan upaya atau tindakan apa saja yang perlu ditingkatkan oleh tim Agile Sevima untuk meningkatkan kinerja dan kualitas dalam menciptakan sebuah sistem informasi yang sukses dengan ruang lingkup yang kompleks.

\section{TINJAUAN PUSTAKA}

\section{A. Inovasi Teknologi di Rumah Sakit.}

Rumah sakit merupakan salah satu bidang pelayanan kesehatan publik yang ditujukkan untuk masyarakat yang ada didalam setiap negara. Industri rumah sakit ini dituntut untuk selalu menyediakan pelayanan kesehatan yang berkualitas tinggi dari waktu ke waktu [9]. Untuk mendukung adanya pelayanan dengan kualitas tinggi tersebut, rumah sakit perlu mengembangkan atau melakukan inovasi terhadap teknologi informasi (TI) yang digunakan untuk kegiatan operasional [2]. Inovasi TI tersebut dapat berupa sistem informasi terintegrasi yang berbasis web ataupun mobile. Rumah sakit tentunya telah memiliki berbagai aplikasi TI atau sistem informasi yang digunakan dengan tujuan dan ruang lingkup yang berbeda [6]. Dimana, sistem informasi tersebut dapat dikategorisasikan menjadi 3 kategori, yaitu sistem informasi untuk klinik, administratif, dan untuk strategic [6]

Sistem informasi yang diterapkan dapat membantu pihak rumah sakit untuk memastikan adanya kecepatan, kemudahan pengelolaan, dan efisiensi layanan rumah sakit [9]. Dengan demikian, penting bagi rumah sakit untuk melakukan inovasi teknologi informasi secara terus menerus, karena dapat meningkatkan performa dan keuntungan bagi pihak rumah sakit.

\section{B. Peningkatan Kepuasan Pengguna.}

Menurut Aggelidis [5], tim pengembang perlu menekankan faktor - faktor kritis yang berpengaruh terhadap kepuasan pengguna. Sistem e-office merupakan sistem kompleks yang dikembangkan secara terus menerus oleh tim Agile Sevima. Adapun hal - hal yang perlu dilakukan oleh tim dalam proses pengembangan sistem informasi yang dapat mendukung peningkatan kepuasan pengguna, antara lain: membangun fungsionalitas sistem sesuai dengan kebutuhan, menguji fungsionalitas sistem, mendokumentasikan hasil, menyelesaikan pekerjaan tepat waktu sesuai dengan rencana, memastikan kualitas dari sistem (contoh: fix bugs, coding review, memastikan kepuasan pengguna) [12]. Selain itu, menurut Drury-Grogan [12], terdapat critical decisions yang perlu diambil oleh tim Agile dalam proses pengembangan sistem, yaitu pembagian 
tugas tim dengan jelas, menangani / mengelola perubahan yang terjadi dengan baik, mengutamakan kualitas. Meningkatnya kepuasan pengguna dipengaruhi oleh kualitas dari kerja tim [13], dimana kualitas kerja tim dipengaruhi oleh komunikasi, koordinasi, keseimbangan kontribusi, dukungan, usaha.

\section{Kesuksesan Sistem Informasi Pada Rumah Sakit.}

Kesuksesan dari sebuah sistem informasi dapat didefinisikan sebagai pencapaian tujuan dari dibangunnya sistem informasi tersebut atau dengan kata lain adanya manfaat yang dirasakan oleh pengguna [8].

Menurut Fowler [14], hanya $28 \%$ sistem informasi yang sukses dan dalam pengembangan sistem informasi tersebut menghabiskan banyak waktu dan biaya yang cukup tinggi.

Penelitian sebelumnya telah mengukur kesuksesan dari sistem informasi pada rumah sakit dengan menyebarkan kuesioner kepada pengguna, dimana kuesioner tersebut mencakup faktor - faktor apa saja yang mempengaruhi kesuksesan sistem informasi yang ada pada rumah sakit [2][4][6][9][10].

1) Faktor Kesuksesan Sistem: Beberapa penelitian terdahulu telah banyak peneliti yang melakukan pengujian terhadap faktor - faktor kesuksesan sistem informasi yang ada didalam rumah sakit. Tujuan dari pengujian faktor faktor kesuksesan tersebut adalah untuk mengetahui dari segi apa pengguna puas terhadap penggunaan sistem informasi tersebut, sehingga diketahui kelebihan dan kekurangan sistem berdasarkan perspektif pengguna.

Sebagian besar peneliti menggunakan model DeLone dan McLean untuk mengukur kesuksesan sistem. Tidak hanya ada satu aspek untuk mengukur kesuksesan tetapi ada banyak yang akhirnya dikategorikan pada 6 aspek: kualitas sistem, kualitas informasi, penggunaan sistem, kepuasan pengguna, dampak individu, dan dampak organisasi [15]. Dalam pengembangan penelitiannya terdahulu, DeLone [15] mengungkapkan bahwa kualitas sistem diukur berdasarkan kemudahan penggunaan sistem, fungsionalitas, keandalan sistem, flexibilitas sistem, kualitas data, integrasi sistem, akurasi data, konten sistem, kemudahan pembelajaran, kemudaan akses, kegunaan fungsi dan fitur sistem, akurasi sistem, fleksibilitas sistem, keandalan sistem, kecanggihan, efisiensi sistem, waktu penyelesaian sistem. Kualitas informasi diukur berdasarkan akurasi, ketepatan waktu, kelengkapan, relevansi, dan konsistensi. Penggunaan sistem diukur dari waktu penggunaan, jumlah sistem diakses, pola penggunaan, dan kebergantungan pengguna terhadap sistem. Kepuasan pengguna diukur berdasarkan kepuasan informasi, kepuasan sistem, kepuasan pengambilan keputusan, kepuasan dinilai secara spesifik, bersamaan, maupun keseluruhan. Yang mana terdiri dari 3 dimensi, yaitu kualitas informasi, kualitas sistem dan kualitas layanan [5][10][16]. Aggelidis [5] menemukan bahwa dimensi kualitas informasi yang mencakup faktor keakuratan informasi, ketepatan waktu, dan format data yang disediakan merupakan faktor kritis yang mempengaruhi kepuasan pengguna sistem informasi rumah sakit. Menurut Cohen [10], kualitas data danlayanan juga menjadi sangat penting untuk produktivitas pengguna. Selain itu, terdapat faktor kesuksesan lain yang diteliti oleh Mahdavian [16] antara lain: kualitas konsultan, dampak individual, dampak organisasi. Sedangkan, Hossain [2] menguji faktor kualitas platform, kualitas interaksi, nilai keuntungan, penggunaan yang terus menerus.

\section{Peningkatan Kepuasan Pengguna}

Menurut Aggelidis [12], tim pengembang perlu menekankan faktor - faktor kritis yang berpengaruh terhadap kepuasan pengguna. Sistem e-office merupakan sistem kompleks yang dikembangkan secara terus menerus oleh tim Agile Sevima. Adapun hal - hal yang perlu dilakukan oleh tim dalam proses pengembangan sistem informasi yang dapat mendukung peningkatan kepuasan pengguna, antara lain: membangun fungsionalitas sistem sesuai dengan kebutuhan, menguji fungsionalitas sistem, mendokumentasikan hasil, menyelesaikan pekerjaan tepat waktu sesuai dengan rencana, memastikan kualitas dari sistem (contoh: fix bugs, review koding, memastikan kepuasan pengguna). Selain itu, menurut Drury-Grogan [13], juga terdapat critical decisions yang perlu diambil oleh tim Agile dalam proses pengembangan sistem, yaitu pembagian tugas tim dengan jelas, menangani / mengelola perubahan yang terjadi dengan baik, mengutamakan kualitas. Meningkatnya kepuasan pengguna dipengaruhi oleh kualitas dari kerja tim, dimana kualitas kerja tim dipengaruhi oleh komunikasi, koordinasi, keseimbangan kontribusi, dukungan, usaha.

1) Faktor Kesuksesan proyek: Faktor kesuksesan proyek ditentukan oleh empat stakeholder utama yaitu manajer proyek, top management, pengguna dan anggota tim. Faktor tersebut antara lain: biaya, waktu dan kualitas adalah hal yang tidak dapat terpisahkan dalam pengukuran kesuksesan dari manajemen proyek [17]. Dari penelitian [18], faktor kesuksesan proyek yang berkaitan dengan waktu dipengaruhi oleh pemahaman terhadap konsep manajemen resiko, kedewasaan tanggung jawab terhadap resiko, kemampuan dalam melihat kemungkinan terjadinya resiko, kemampuan dalam rencana perubahan manajemen resiko. Sedangkan [15] faktor kesuksesan proyek yang berkaitan dengan kualitas dipengaruhi oleh kualitas sistem informasi, penggunaan informasi, kepuasan pengguna, dampak individu maupun organisasi.

\section{E. Penelitian Sebelumnya}

Pembahasan sebelumnya telah dijelaskan bahwa rumusan masalah dari penelitian ini mencakup 2 hal, yaitu (1) faktor - faktor kesuksesan apa saja yang dapat mempengaruhi kesuksesan sistem $e$-office. Telah disebutkan bahwa faktor kesuksesan sistem dipengaruhi oleh kualitas 
sistem [5][4][10][16], kualitas informasi [5][4], kualitas data [4], kualitas layanan [4][10][16], kualitas platform, kualitas Interaksi, nilai keuntungan, frekuensi dalam penggunaan sistem [2], kualitas konsultan, dan dampak individu dan organisasi [16].

Sedangkan, untuk upaya yang dilakukan oleh tim Agile dalam meningkatkan kesuksesan sistem juga telah dibahas pada penelitian sebelumnya, yaitu : membangun fungsionalitas sistem sesuai dengan kebutuhan, menguji fungsionalitas sistem, mendokumentasikan hasil, menyelesaikan pekerjaan tepat waktu sesuai dengan rencana, memastikan kualitas dari sistem, pembagian tugas tim dengan jelas, menangani / mengelola perubahan yang terjadi dengan cepat dan tepat [12], serta meningkatkan komunikasi dan koordinasi, menyeimbangkan keseimbangan kontribusi, adanya motivasi antar anggota tim, adanya usaha yang maksimal [13]. Selain itu, Chow [19] juga menemukan faktor - faktor yang dapat mendorong tim Agile untuk menciptakan sistem yang sukses, antara lain : 1) strategi untuk mengelola fitur mana yang perlu dikembangkan terlebih dahulu; 2) teknik pengembangan Agile yang baik (contoh : standar koding yang terdefinisi dengan baik, desain sistem yang mudah dipahami, dokumentasi yang benar, testing yang tepat); kemampuan tim (kompetensi yang tinggi, adanya motivasi yang tinggi, manajer memiliki pengetahuan yang baik tentang teknik pengembangan Agile, gaya kepemimpinan manajer yang baik, adanya training untuk tim); 3) proses manajemen proyek yang baik (berfokus pada komunikasi dengan melakukan rapat progres setiap hari dan menyesuaikan dengan jadwal rencana proyek); 4) anggota tim yang mampu mengatur pekerjaannya sendiri; 5) adanya hubungan baik dengan klien dan komitmen yang kuat dari klien.

Kesenjangan yang terdapat pada penelitian sebelumnya dengan penelitian ini adalah pada penelitian sebelumnya sebagian besar mengacu pada teori dan sudut pandang akademik untuk mendapatkan faktor - faktor apa saja yang berpengaruh terhadap kepuasan penggunaan sistem informasi. Sedangkan, penelitian ini tidak hanya mengacu pada teori dan akademik saja, namun juga melihat sudut pandang praktisi. Peneliti melakukan pengambilan data dari sebuah perusahaan konsultan TI, yaitu PT. Sevima yang merupakan pengembang dari sistem e-office. Peneliti melihat sudut pandang praktisi terkait aspek apa saja yang digunakan untuk mengukur kepuasan pengguna terhadap penggunaan sistem e-office dan apa saja yang selama ini dilakukan dalam pengembangan sistem $e$-office.

\section{METODOLOGI}

Penelitian ini menggunakan pendekatan studi kasus, dimana peneliti mengeksplorasi fenomena tertentu (kasus) dalam waktu dan kegiatan (program, acara, proses, lembaga, atau kelompok sosial) dan mengumpulkan informasi rinci dan mendalam menggunakan berbagai prosedur pengumpulan data [1]. Menurut Yin, ada enam bentuk pengumpulan data dalam studi kasus, yaitu : (1) dokumen; (2) rekaman arsip; (3) wawancara terbuka; (4) observasi langsung; (5) observasi partisipan dan (6) peralatan atau instrumen teknologi [2]. Pada penelitian ini, metode yang digunakan adalah wawancara, observasi langsung, analisis dokumen, serta melakukan kajian pada penelitian sebelumnya. Berikut adalah bagan metodologi penelitian yang digunakan (Gambar 1).

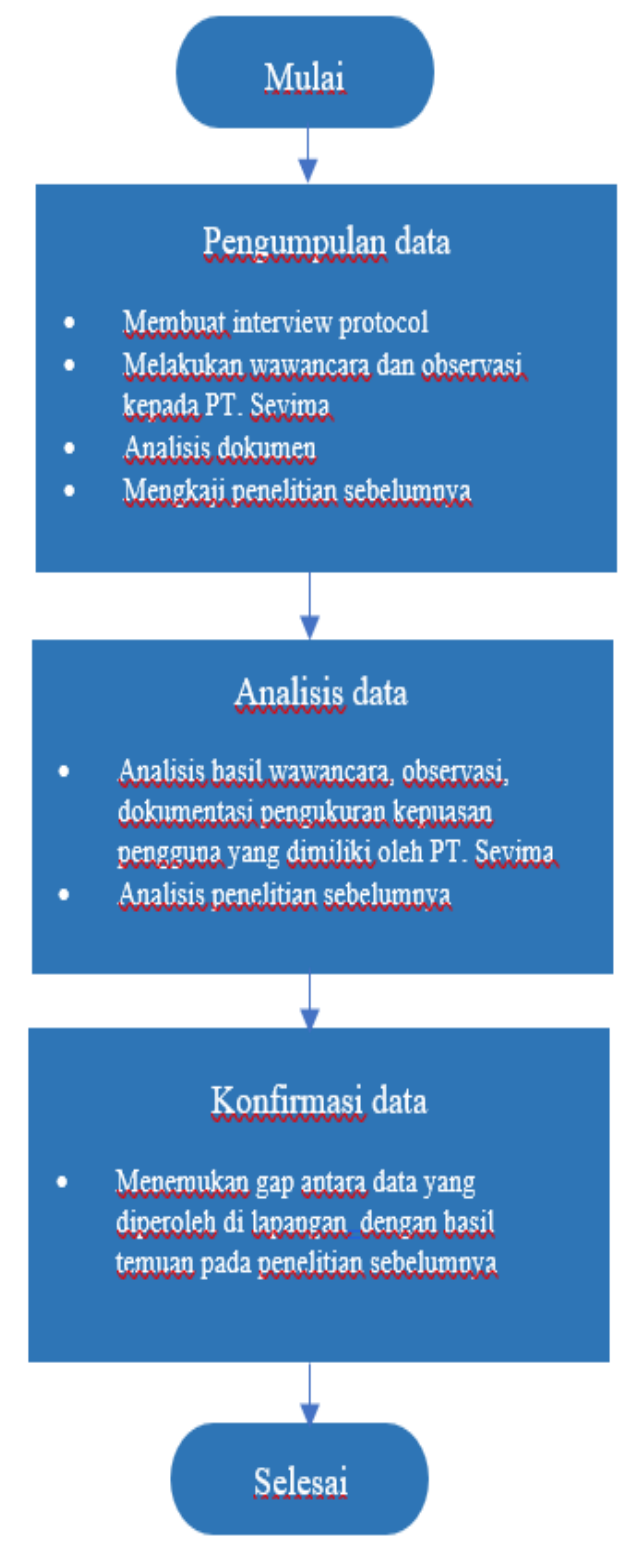

Gambar 1. Metodologi Penelitian

\section{A. Pengumpulan data}

Peneliti melakukan pengumpulan data melalui wawancara mendalam, observasi langsung, analisis dokumen dan analisis pada beberapa penelitian sebelumnya. 
Pengumpulan data dilakukan untuk mengetahui informasi rinci terkait hal - hal apa saja yang selama ini dilakukan oleh tim Sevima untuk meningkatkan kesuksesan implementasi sistem e-office dan indikator apa saja yang menjadi ukuran kepuasan pengguna e-office. Peneliti membuat interview protocol terlebih dahulu sebagai pedoman dalam melakukan wawancara. Berikut adalah area pertanyaan dari interview protocol yang telah dibangun oleh peneliti (Tabel I) .

TABEL I

AREA PERTANYAAN INTERVIEW PROTOCOL

\begin{tabular}{|c|l|}
\hline No. & \multicolumn{1}{|c|}{ Pertanyaan Mengenai } \\
\hline 1. & $\begin{array}{l}\text { Identifikasi divisi RSUPN Dr. Cipto } \\
\text { Mangunkusumo }\end{array}$ \\
\hline 2. & $\begin{array}{l}\text { Divisi yang memiliki proses yang paling } \\
\text { kompleks }\end{array}$ \\
\hline 3. & Tantangan selama proses pengembangan \\
\hline 4. & $\begin{array}{l}\text { Hal yang dilakukan tim dalam menghadapi } \\
\text { tantangan membangun }\end{array}$ \\
\hline 5. & $\begin{array}{l}\text { Kesulitan tim dalam membangun } \\
\text { fungsionalitas sistem }\end{array}$ \\
\hline 6. & $\begin{array}{l}\text { Bagaimana cara tim } \\
\text { fungsionalitas sistem }\end{array}$ \\
\hline 7 & $\begin{array}{l}\text { Bagaimana tim mengelola } \\
\text { pengerjaan }\end{array}$ \\
\hline 8. & $\begin{array}{l}\text { Bagaimana cara tim mengukur kepuasan } \\
\text { pengguna }\end{array}$ \\
\hline 9. & $\begin{array}{l}\text { Tindakan yang dilakukan tim dalam } \\
\text { meningkatkan kepuasan pengguna }\end{array}$ \\
\hline 10. & $\begin{array}{l}\text { Bagaimana cara tim mengukur kepuasan } \\
\text { pengguna }\end{array}$ \\
\hline 11. & Indikator mengukur kepuasan pengguna \\
\hline 12. & Divisi yang memiliki kepuasan tertinggi \\
\hline 13. & Divisi yang memiliki kepuasan terendah \\
\hline 14. & $\begin{array}{l}\text { Perbandingan presentase kepuasan tertinggi } \\
\text { dan terendah }\end{array}$ \\
\hline & \\
\hline
\end{tabular}

Narasumber yang diwawancarai terdiri dari orang yang bertanggung jawab terhadap berjalannya pengembangan proyek e-office dan orang yang memahami proses bisnis dari $e$-office dan ikut mengembangkan sistem ini dari awal hingga saat ini. Mereka adalah manajer proyek dan sistem analis. Wawancara dilakukan dengan bertatap muka secara langsung dan melalui chating.

Observasi dilakukan dengan mengamati kondisi lingkungan kerja yang ada dalam tim Agile Sevima yang mengembangkan sistem e-office. Sementara, untuk penggalian dokumen adalah semua dokumentasi yang terkait dengan hasil pengukuran kepuasan pengguna, yaitu perangkat kuesioner yang digunakan untuk mengukur kepuasan pengguna, hasil penggunaan sistem e-office selama ini yang dilihat dari seberapa banyak surat yang diproses oleh setiap divisi. Selanjutnya, dilakukan pengkajian pada penelitian sebelumnya tentang faktor faktor yang mempengaruhi kepuasan pengguna pada suatu sistem.

\section{B. Analisis data}

Setelah semua data terkumpul, peneliti melakukan analisis pada hasil wawancara, observasi dan hasil penggalian data dari dokumentasi yang berkaitan dengan hasil pengukuran kepuasan pengguna, serta analisis pada beberapa penelitian sebelumnya. Tujuan dari analisis data ini adalah mengolah data yang telah diperoleh, sehingga dapat menjadi informasi yang bermanfaat bagi peneliti. Analisis data dimulai dengan memilah, memahami, menyimpulkan, dan mencatat hal - hal yang dapat menjawab rumusan masalah dari penelitian ini.

\section{Konfirmasi data}

Tahapan ini dilakukan dengan tujuan untuk mengkonfirmasi apakah data yang diperoleh di lapangan sesuai dengan dasar teori atau hasil temuan pada beberapa penelitian sebelumnya. Konfirmasi data dilakukan dengan membandingkan hasil analisis data dilapangan dan data yang diperoleh dari penelitian sebelumnya.

Selanjutnya, menemukan kesenjangan dari keduanya dan menyimpulkan dan mendaftar rekomendasi hal - hal apa saja yang perlu dilakukan tim pengembang dalam mengembangkan sebuah sistem yang kompleks serta aspek apa saja yang perlu digunakan untuk mengukur kepuasan pengguna.

\section{HASIL DAN PEMBAHASAN}

Bab ini akan memaparkan hasil pengumpulan data beserta analisis data dan pembahasan dari hasil analisis data tersebut.

\section{A. Pengukuran Kepuasan Pengguna}

Tim Agile Sevima telah melakukan pengukuran kepuasan pengguna secara terus menerus setiap tahun dari awal tahun implementasi e-office. Tim ini menyebarkan kuesioner kepada seluruh divisi Rumah Sakit Umum Pusat Nasional (RSUPN) Dr. Cipto Mangunkusumo yang telah mengoperasikan e-office untuk mengukur kepuasan pengguna. Pengukuran menggunakan kuesioner ini telah dilakukan oleh beberapa penelitian sebelumnya, dimana kuesioner terdiri dari beberapa pertanyaan yang mencakup faktor - faktor yang dapat mempengaruhi kesuksesan sistem informasi yang ada pada rumah sakit [3][4][5][6][7].

Dari hasil pengumpulan data yang telah dilakukan oleh peneliti, juga didapatkan sebuah kuesioner yang digunakan oleh tim Agile Sevima untuk mengetahui atau mengukur kepuasan pengguna e-office. Kuesioner tersebut terdiri dari 2 kategori pertanyaan, yaitu mengenai pelayanan yang telah diberikan oleh tim Agile Sevima dan kemudahan fitur - fitur yang disediakan oleh sistem $e$-office.

Kuisioner pertama merupakan kuesioner tentang pelayanan yang telah diberikan oleh tim Agile Sevima yang mana membahas (1) mengenai respons tim terhadap aduan 
kendala penggunaan; (2) ketepatan tim memberikan solusi; (3) pendampingan dalam memahami alur penggunaan $e$ office; (4) kebutuhan penambahan waktu dalam pendampingan; (5) kepuasan layanan tim; (6) kritik dan saran dalam upaya peningkatan pelayanan.

Sedangkan pada kuisioner kedua merupakan kuesioner tentang kemudahan fitur - fitur e-office, yang mana membahas (1) apakah fitur-fitur e-office dapat membantu dan mempermudah pekerjaan; (2) apakah fitur yang disediakan sesuai dengan kebutuhan manajemen surat; (3) kemudahan mempelajari fitur dalam operasional kerja; (4) kemudahan penggunaan fitur; (5) kepuasan fitur yang tersedia; (6) kritik dan saran peningkatan fitur.

Berdasarkan kuesioner yang dibangun oleh pihak tim Agile Sevima, maka dapat ditemukan faktor - faktor yang digunakan oleh tim untuk mengukur kepuasan pengguna. Selanjutnya, dilakukan konfirmasi terhadap data pertanyaan dari kuesioner dengan faktor - faktor kesuksesan sistem yang telah ditemukan pada penelitian sebelumnya.

1) Faktor - Faktor Kesuksesan Sistem E-Office: Data pertanyaan kuesioner yang telah diperoleh peneliti, selanjutnya dilakukan analisis dan justifikasi, serta dikategorisasikan kedalam faktor - faktor kesuksesan sistem informasi yang telah ditemukan dari beberapa penelitian sebelumnya. Justifikasi faktor dapat dilihat pada Tabel II. Setelah dilakukan justifikasi, maka ditemukan faktor faktor kesuksesan sistem informasi, antara lain: kualitas sistem, kualitas informasi, kualitas data, kualitas layanan, kualitas platform, kualitas interaksi, nilai keuntungan, continuous intention, kualitas konsultan, dampak individual, dampak organisasi.

TABEL II

JUSTIFIKASI FAKTOR KESUKSESAN

\begin{tabular}{|c|c|c|}
\hline No. & Pertanyaan Kuesioner & $\begin{array}{ll}\text { Justifikasi } & \text { Faktor } \\
\text { Kesuksesan } & \\
\end{array}$ \\
\hline 1. & Respons tim & 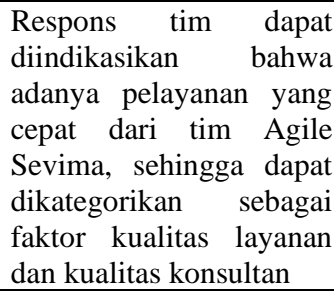 \\
\hline 2. & $\begin{array}{l}\text { Ketepatan menyelesaikan } \\
\text { masalah }\end{array}$ & $\begin{array}{l}\text { Ketepatan menyelesaikan } \\
\text { masalah dapat } \\
\text { diindikasikan bahwa } \\
\text { adanya pelayanan dari } \\
\text { tim Agile Sevima yang } \\
\text { tepat dalam menangani } \\
\text { complain dari pengguna, } \\
\text { sehingga juga dapat } \\
\text { dikategorikan sebagai } \\
\text { faktor kualitas layanan }\end{array}$ \\
\hline
\end{tabular}

JuTISI

\begin{tabular}{|c|c|c|}
\hline No. & Pertanyaan Kuesioner & $\begin{array}{ll}\text { Justifikasi } & \text { Faktor } \\
\text { Kesuksesan } & \end{array}$ \\
\hline & & dan kualitas konsultan \\
\hline 3. & $\begin{array}{l}\text { Pendampingan } \\
\text { pemahaman }\end{array}$ & $\begin{array}{l}\text { Pendampingan } \\
\text { pemahaman dapat } \\
\text { dikategorisasikan } \\
\text { kedalam kualitas layanan } \\
\text { dan kualitas konsultan. } \\
\text { Selain itu, menurut } \\
\text { Aggelidis, pendampingan } \\
\text { atau training juga dapat } \\
\text { dikategorisasikan } \\
\text { kedalam kualitas sistem } \\
\text { [5]. }\end{array}$ \\
\hline 4. & $\begin{array}{l}\text { Penambahan } \\
\text { pendampingan }\end{array}$ & $\begin{array}{lr}\text { Sama halnya dengan } \\
\text { pertanyaan nomor (3). } \\
\text { Pertanyaan nomor (4) ini } \\
\text { dapat dikategorisasikan } \\
\begin{array}{ll}\text { kedalam } & \text { kualitas } \\
\text { layanan, } & \text { kualitas } \\
\text { konsultan, dan } & \text { kualitas } \\
\text { sistem. }\end{array}\end{array}$ \\
\hline 5. & $\begin{array}{l}\text { Penilaian kemudahan } \\
\text { operasional kerja }\end{array}$ & \begin{tabular}{lr} 
Penilaian & \multicolumn{2}{r}{ kemudahan } \\
operasional kerja dapat & dahwa \\
diindikasikan & bahwa \\
adanya & kemudahan \\
penggunaan & sistem, \\
sehingga & dapat \\
dikategorisasikan & \\
kedalam kualitas sistem.
\end{tabular} \\
\hline 6. & Fitur yang disediakan & \multirow{3}{*}{$\begin{array}{l}\text { Pertanyaan nomor 6-8 } \\
\text { merupakan pertanyaan } \\
\text { yang mengukur } \\
\text { kemudahan dan kepuasan } \\
\text { fitur - fitur yang } \\
\text { disediakan oleh sistem } e- \\
\text { office, sehingga dapat } \\
\text { dikategorisasikan } \\
\text { kedalam faktor kualitas } \\
\text { sistem. }\end{array}$} \\
\hline 7. & $\begin{array}{l}\text { Kemudahan mempelajari } \\
\text { fitur }\end{array}$ & \\
\hline 8. & $\begin{array}{l}\text { Penilaian kepuasan fitur } \\
\text { yang tersedia }\end{array}$ & \\
\hline
\end{tabular}

2) Konfirmasi Faktor Kesuksesan Sistem E-Office: Peneliti melakukan konfirmasi hasil analisis faktor - faktor kesuksesan sistem e-office yang didapatkan dari pengumpulan data dengan penelitian sebelumnya. Konfirmasi dilakukan dengan memetakan antara faktor kesuksesan sistem dari tim Agile Sevima dengan faktor kesuksesan dari penelitian sebelumnya. Tujuan dari konfirmasi ini adalah untuk mengetahui kesenjangan dan faktor - faktor apa saja yang belum dilibatkan oleh tim Agile Sevima dalam mengukur kepuasan pengguna, sehingga untuk selanjutnya dapat dipertimbangkan untuk digunakan oleh tim Agile Sevima.

Faktor pengukuran kesuksesan sistem yang digunakan oleh tim Agile Sevima hanya terdiri dari 3 faktor, yaitu kualitas sistem: mudah digunakan, kecepatan sistem, dokumentasi, interface, training, kualitas layanan, dan kualitas konsultan. Adapun faktor kesuksesan yang belum 
dilibatkan oleh tim Sevima antara lain: kualitas informasi (akurasi, format, ketepatan waktu), kualitas data, kualitas platform, kualitas interaksi, nilai keuntungan, penggunaan yang terus menerus, kualitas konsultan, dampak individu dan organisasi._Hal ini juga dapat mengindikasikan bahwa pertanyaan kuesioner yang telah dibangun oleh tim Agile Sevima terkait e-office kurang mendalam dan mendetil. Sehingga pada bagian ini dapat diusulkan agar tim Agile Sevima menambahkan faktor_kualitas informasi (akurasi, format, ketepatan waktu), kualitas data, kualitas platform, kualitas interaksi, nilai keuntungan sistem, frekuensi dalam penggunaan sistem, kualitas konsultan, dampak bagi individu dan organisasi untuk mengukur kepuasan pengguna sistem e-office.

\section{B. Upaya yang dilakukan oleh Tim Agile Sevima}

Berdasarkan hasil pengumpulan data yang dilakukan melalui wawancara, telah didapatkan informasi terkait upaya atau hal - hal apa saja yang selama ini telah dilakukan oleh tim Agile Sevima dalam mengembangkan $e$ office. Tabel III memaparkan upaya apa saja yang telah dilakukan untuk menciptkan sistem e-office yang sukses sehingga dapat mempengaruhi kepuasan pengguna.

TABEL IIII

DAFTAR UPAYA YANG DILAKUKAN OLEH TIM AGILE SEVIMA

\begin{tabular}{|c|c|}
\hline No. & $\begin{array}{l}\text { Upaya yang dilakukan oleh Tim Agile } \\
\text { Sevima (Berdasarkan hasil wawancara) }\end{array}$ \\
\hline 1. & $\begin{array}{l}\text { Melakukan pembagian jobdesk, yang } \\
\text { terdiri dari sistem analis, programmer, } \\
\text { dokumentator, dan implementator. }\end{array}$ \\
\hline 2. & $\begin{array}{l}\text { Projek manajer memahami proses teknik } \\
\text { pengembangan sistem menggunakan } \\
\text { teknik Agile dengan baik dan } \\
\text { mengupayakan untuk mengatur anggota } \\
\text { tim dengan baik }\end{array}$ \\
\hline 3. & $\begin{array}{l}\text { Menyesuaikan kebutuhan sistem dengan } \\
\text { Kerangka Acuan Kerja (KAK) dari } \\
\text { kementerian kesehatan. }\end{array}$ \\
\hline 4. & $\begin{array}{l}\text { Selalu mengikuti jadwal yang telah } \\
\text { tertulis di Kerangka Acuan Kerja (KAK) } \\
\text { dari kementerian kesehatan. }\end{array}$ \\
\hline 5 & $\begin{array}{l}\text { Melakukan sprint setiap } 2 \text { minggu sekali } \\
\text { agar pengerjaan sistem dapat selesai tepat } \\
\text { waktu. }\end{array}$ \\
\hline 6. & $\begin{array}{l}\text { Untuk pengelolaan kualitas sistem, tim } \\
\text { melakukan UAT (User Acceptance Test) } \\
\text { per sprint, senior manajer melakukan } \\
\text { review pada kodingan, setalah itu quality } \\
\text { assurance sebagai tester untuk menguji } \\
\text { fungsionalitas sistem sesuai kasus atau } \\
\text { skenario yang telah dibuat }\end{array}$ \\
\hline 7. & $\begin{array}{l}\text { Meningkatkan kualitas pelayanan, } \\
\text { mendokumentasikan hasil pengembangan } \\
\text { sistem dan update dokumentasi user } \\
\text { manual, peningkatan kualitas sistem } \\
\text { dengan meningkatkan standard kodingan } \\
\text { (improvement) }\end{array}$ \\
\hline
\end{tabular}

\begin{tabular}{|c|l|}
\hline No. & $\begin{array}{l}\text { Upaya yang dilakukan oleh Tim Agile } \\
\text { Sevima (Berdasarkan hasil wawancara) }\end{array}$ \\
\hline 8. & $\begin{array}{l}\text { Melakukan validasi untuk setiap hasil } \\
\text { komunikasi / perubahan yang terjadi }\end{array}$ \\
\hline 9. & $\begin{array}{l}\text { Melakukan maintenance secara rutin } \\
\text { tahunan, sesuai kontrak kerja di KAK) } \\
\text { yang meliputi Scope Maintenance, } \\
\text { Checking, Patch Fixing, Tanya Jawab / } \\
\text { FAQ }\end{array}$ \\
\hline 10. & $\begin{array}{l}\text { Melakukan Transfer of Knowledge } \\
\text { karena tim yang bertanggung jawab } \\
\text { terhadap proyek bersifat dinamis (karena } \\
\text { turnover pegawai cukup tinggi) }\end{array}$ \\
\hline
\end{tabular}

1) Konfirmasi Upaya Tim Agile Sevima: untuk upaya tim Agile Sevima juga dilakukan konfirmasi dengan penelitian sebelumnya untuk mengetahui kesenjangan antara yang telah diimplementasikan oleh tim Agile dengan hasil penelitian sebelumnya. Hasil konfirmasi tersebut dapat dipetakan pada Tabel IV.

TABEL IIIV

PEMETAAN UPAYA TIM AGILE SEVIMA

\begin{tabular}{|c|c|}
\hline $\begin{array}{l}\text { Upaya yang dilakukan oleh } \\
\text { Tim Pengembang Sistem } \\
\text { (Berdasarkan Penelitian } \\
\text { Sebelumnya) }\end{array}$ & $\begin{array}{lr}\text { Upaya yang } & \text { dilakukan } \\
\text { oleh Tim Pengembang } \\
\text { Sistem } \\
\text { (Berdasarkan } \\
\text { Wawancara) }\end{array}$ \\
\hline $\begin{array}{l}\text { Membangun fungsionalitas } \\
\text { sistem sesuai dengan } \\
\text { kebutuhan [7] }\end{array}$ & $\begin{array}{l}\text { Menyesuaikan kebutuhan } \\
\text { sistem dengan Kerangka } \\
\text { Acuan Kerja (KAK) dari } \\
\text { kementerian kesehatan. }\end{array}$ \\
\hline $\begin{array}{ll}\text { Menguji } & \text { fungsionalitas } \\
\text { sistem [7] } & \end{array}$ & \begin{tabular}{l} 
Melakukan Quality \\
assurance untuk menguji \\
fungsionalitas sistem \\
sesuai kasus atau skenario \\
\multicolumn{2}{l}{ yang telah dibuat }
\end{tabular} \\
\hline $\begin{array}{l}\text { Mendokumentasikan hasil } \\
\text { dengan benar [7][8] }\end{array}$ & $\begin{array}{l}\text { Mendokumentasikan hasil } \\
\text { pengembangan sisten dan } \\
\text { selalu update dokumentasi } \\
\text { user manual }\end{array}$ \\
\hline $\begin{array}{l}\text { Menyelesaikan pekerjaan } \\
\text { tepat waktu sesuai dengan } \\
\text { rencana [7] [8] }\end{array}$ & $\begin{array}{lrr}\text { - Selalu } & \text { mengikuti } \\
\text { jadwal yang telah } & \text { tertulis di Kerangka } \\
\text { Acuan } & \text { Kerja } \text { (KAK) } \\
\text { dari } & \text { kementerian } \\
\text { kesehatan. } & \\
\text { - } & \text { Melakukan } \quad \text { sprint } \\
\text { setiap } 2 \text { minggu sekali } \\
\text { agar pengerjaan sistem } \\
\text { dapat selesai tepat } \\
\text { waktu. }\end{array}$ \\
\hline
\end{tabular}




\begin{tabular}{|c|c|}
\hline $\begin{array}{l}\text { Upaya yang dilakukan oleh } \\
\text { Tim Pengembang Sistem } \\
\text { (Berdasarkan Penelitian } \\
\text { Sebelumnya) }\end{array}$ & $\begin{array}{lr}\text { Upaya yang } & \text { dilakukan } \\
\text { oleh Tim Pengembang } \\
\text { Sistem } \\
\text { (Berdasarkan } & \\
\text { Wawancara) } & \\
\end{array}$ \\
\hline $\begin{array}{l}\text { Memastikan kualitas dari } \\
\text { sistem dengan melakukan } \\
\text { testing (contoh : fix bugs, } \\
\text { review koding, memastikan } \\
\text { kepuasan pengguna) [7][8] }\end{array}$ & $\begin{array}{l}\text { - Untuk pengelolaan } \\
\text { kualitas sistem, tim } \\
\text { melakukan UAT (User } \\
\text { Acceptance Test) per } \\
\text { sprint, senior manajer } \\
\text { melakukan review } \\
\text { pada kodingan, setalah } \\
\text { itu quality assurance } \\
\text { sebagai tester untuk } \\
\text { menguji fungsionalitas } \\
\text { sistem sesuai kasus } \\
\text { atau skenario yang } \\
\text { telah dibuat } \\
\text { Melakukan } \\
\text { maintenance secara } \\
\text { rutin (tahunan, sesuai } \\
\text { kontrak kerja di KAK) } \\
\text { yang meliputi Scope } \\
\text { Maintenance, } \\
\text { Checking, Patch } \\
\text { Fixing k } \\
\text { Peningkatan kualitas } \\
\text { sistem dengan } \\
\text { meningkatkan } \\
\text { standard kodingan } \\
\text { (improvement) }\end{array}$ \\
\hline $\begin{array}{l}\text { Pembagian tugas tim yang } \\
\text { jelas [7] }\end{array}$ & 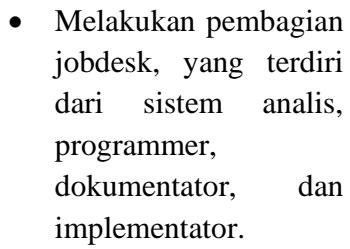 \\
\hline $\begin{array}{l}\text { Menangani / mengelola } \\
\text { perubahan yang terjadi } \\
\text { dengan cepat dan tepat [7] }\end{array}$ & $\begin{array}{l}\text { Meningkatkan kualitas } \\
\text { pelayanan, Tanya Jawab / } \\
\text { FAQ }\end{array}$ \\
\hline $\begin{array}{l}\text { Meningkatkan komunikasi } \\
\text { dan koordinasi tim [9][8] }\end{array}$ & $\begin{array}{l}\text { Melakukan sprint / rapat } \\
\text { progress setiap } 2 \text { minggu } \\
\text { sekali agar pengerjaan } \\
\text { sistem dapat selesai tepat } \\
\text { waktu. }\end{array}$ \\
\hline $\begin{array}{l}\text { Menyeimbangkan } \\
\text { keseimbangan kontribusi [9] }\end{array}$ & $X$ \\
\hline $\begin{array}{l}\text { Adanya motivasi antar tim } \\
\text { [8] [9] }\end{array}$ & $\mathrm{X}$ \\
\hline $\begin{array}{l}\text { Adanya usaha yang maksimal } \\
\text { dari anggota tim [8]; Anggota } \\
\text { tim yang mampu mengatur } \\
\text { pekerjaannya sendiri [9] }\end{array}$ & $\mathrm{X}$ \\
\hline
\end{tabular}

\begin{tabular}{|c|c|}
\hline $\begin{array}{l}\text { Upaya yang dilakukan oleh } \\
\text { Tim Pengembang Sistem } \\
\text { (Berdasarkan } \\
\text { Sebelumnya) }\end{array}$ & $\begin{array}{lr}\text { Upaya yang } & \text { dilakukan } \\
\text { oleh Tim Pengembang } \\
\text { Sistem } \\
\text { (Berdasarkan } & \\
\text { Wawancara) } & \text { Hasil } \\
\end{array}$ \\
\hline $\begin{array}{lr}\text { Strategi untuk } & \text { mengelola } \\
\text { fitur mana yang perlu } \\
\text { dikembangkan } & \text { terlebih } \\
\text { dahulu [8] } & \end{array}$ & $X$ \\
\hline $\begin{array}{l}\text { Standar koding yang } \\
\text { terdefinisi dengan baik dan } \\
\text { desain sistem yang mudah } \\
\text { dipahami }[8]\end{array}$ & $\bar{X}$ \\
\hline $\begin{array}{lrr}\begin{array}{l}\text { Manajer } \\
\text { pengetahuan }\end{array} \text { yang } \begin{array}{r}\text { baik } \\
\text { teknik }\end{array} \\
\text { tentang } & \text { tang } \\
\text { pengembangan } & \text { Agile, gaya } \\
\text { kepemimpinan manajer yang } \\
\text { baik [8] }\end{array}$ & $\begin{array}{lr}\text { Projek manajer } \\
\text { memahami proses } & \text { teknik } \\
\text { pengembangan } & \text { sistem } \\
\text { menggunakan teknik } & \text { Agile dengan baik dan } \\
\text { mengupayakan untuk } \\
\text { mengatur anggota tim } \\
\text { dengan baik }\end{array}$ \\
\hline $\begin{array}{l}\text { Adanya training untuk tim } \\
\text { [8] }\end{array}$ & $\mathrm{X}$ \\
\hline $\begin{array}{l}\text { Berfokus pada komunikasi } \\
\text { dengan melakukan rapat } \\
\text { progres setiap hari }\end{array}$ & $X$ \\
\hline $\begin{array}{l}\text { Adanya hubungan baik } \\
\text { dengan klien dan komitmen } \\
\text { yang kuat dari klien [8] }\end{array}$ & \begin{tabular}{lr} 
- & \multicolumn{2}{l}{ Melakukan } & validasi \\
untuk setiap & hasil \\
komunikasi r & perubahan \\
terjadi & yang \\
- & Tanya Jawab klien \\
dan tim melalui grup \\
WhatsApp terkait \\
sistem
\end{tabular} \\
\hline
\end{tabular}

Tabel IV ditemukan kesenjangan yang terjadi antara yang telah diimplementasikan oleh tim Agile dengan hasil penelitian sebelumnya. Sebagian besar upaya yang telah dilakukan oleh tim Agile Sevima untuk menciptakan sistem yang sukses telah terpetakan pada penelitian sebelumnya, kecuali 1) Menyeimbangkan keseimbangan kontribusi; 2) Adanya motivasi antar tim; 3) Adanya usaha yang maksimal dari anggota tim; 4) Anggota tim yang mampu mengatur pekerjaannya sendiri; 5) Strategi untuk mengelola fitur mana yang perlu dikembangkan terlebih dahulu; 6) Standar koding yang terdefinisi dengan baik dan desain sistem yang mudah dipahami 7) Adanya training untuk tim; 8) Berfokus pada komunikasi dengan melakukan rapat progres setiap hari. Beberapa upaya tersebut mungkin belum dilakukan oleh tim Agile Sevima dengan maksimal, namun dapat disimpulkan bahwa tim Agile telah berupaya semaksimal mungkin untuk menciptakan sistem e-office yang dapat dioperasikan dengan baik dan memaksimalkan pelayanan terutama pada keluhan atau komplain yang disampaikan oleh pengguna.

Dengan demikian, pada bagian ini dapat mengusulkan upaya atau tindakan apa yang yang penting dilakukan oleh 
tim pengembang Agile dalam upaya menciptakan kesuksesan sistem dan mendorong terciptanya kepuasan pengguna.

\section{KESIMPULAN}

Faktor kesuksesan sistem informasi merupakan faktor penting yang perlu diukur untuk mengetahui dari segi apa pengguna puas terhadap penggunaan sistem informasi tersebut dan dapat diketahui kelebihan dan kekurangan sistem berdasarkan perspektif pengguna. Adapun upaya atau hal - hal yang perlu dilakukan tim pengembang sistem informasi agar sukses dalam proses pengembangan sistem sehingga dapat mendorong adanya kepuasan pengguna. Penelitian ini telah menghasilkan: 1) faktor - faktor kesuksesan sistem informasi yang perlu ditambahkan untuk mengevaluasi kepuasan pengguna terhadap e-office. Faktor tersebut antara lain: kualitas informasi (akurasi, format, ketepatan waktu), kualitas data, kualitas platform, kualitas interaksi, nilai keuntungan sistem, frekuensi dalam penggunaan sistem, kualitas konsultan, dampak bagi individu dan organisasi; 2) rekomendasi bagi tim Agile Sevima terkait upaya atau tindakan apa saja yang perlu ditingkatkan. Upaya atau tindakan tersebut antara lain: menyeimbangkan keseimbangan kontribusi, saling memotivasi, usaha yang maksimal dari anggota tim, anggota tim mampu mengatur pekerjaannya sendiri, membuat strategi untuk mengelola fitur mana yang perlu dikembangkan terlebih dahulu, memiliki standar koding yang terdefinisi dengan baik dan desain sistem yang mudah dipahami, mengikuti pelatihan yang berkelanjutan, berfokus pada komunikasi dengan melakukan rapat progres setiap hari.

Konfirmasi antara data dilapangan dengan data temuan dari penelitian sebelumnya merupakan kontribusi teoritis dari penelitian ini. Sedangkan, untuk kontribusi praktis dari penelitian ini adalah dapat digunakan tim Agile Sevima atau tim pengembang sistem informasi lain untuk dapat menggunakan faktor - faktor kesuksesan yang ada pada penelitian ini guna mengukur kepuasan pengguna dan tindakan atau upaya apa saja yang perlu dilakukan agar sistem informasi tersebut sukses dibangun dan diimplementasikan.

Penelitian ini menghasilkan sebuah novelty, yaitu telah menghasilkan rekomendasi berupa faktor dan indikator yang dapat digunakan oleh organisasi untuk mengevaluasi penggunaan sistem informasi. Faktor dan indikator tersebut ditemukan dari 2 sudut pandang, yaitu praktisi dan akademik. Selain itu, juga menghasilkan daftar rekomendasi upaya yang dapat dilakukan oleh organisasi dalam meningkatkan kinerja untuk menghasilkan sistem informasi yang berkualitas. Daftar rekomendasi tersebut juga didapatkan dari sudut pandang praktisi dan akademik.

Penelitian ini terbatas pada pengumpulan data pada satu studi kasus, yaitu salah satu tim Agile yang ada di Sevima yang telah mengembangkan sistem e-office. Selain itu, belum mendetilkan faktor kesuksesan dan upaya yang perlu dilakukan. Dengan demikian, untuk penelitian selanjutnya perlu mendetilkan faktor - faktor kesuksesan sistem dan melengkapi upaya apa saja yang perlu dilakukan oleh tim pengembang sistem informasi, serta jika memungkinkan dapat dilakukan simulasi terhadap faktor kesuksesan dan upaya tersebut.

\section{UCAPAN TERIMA KASIH}

Peneliti berterimakasih kepada PT. Sentra Vidya Utama (Sevima) Surabaya yang telah mengijinkan kami melakukan wawancara kepada salah satu tim pengembang e-office. Kami juga berterimakasi kepada tim pengembang (tim Agile) e-office tersebut karena telah meluangkan waktunya dan memberikan informasi yang sangat bermanfaat bagi peneliti.

\section{DAFTAR PUSTAKA}

[1] H. Ahmadi, M. Nilashi, Leila Shahmoradi, and Othman Ibrahim "Hospital Information System Adoption: Expert perspectives on an adoption framework for Malaysian public hospitals," Computers in Human Behavior, vol. 67, pp. 161-189, 2016, doi: https://doi.org/10.1016/j.chb.2016.10.023.

[2] M. A. Hossain, "Assessing m-Health success in Bangladesh: An empirical investigation using IS success models," Journal of Enterprise Information Management, vol. 29, no. 5, pp. 774-796, 2016, doi: https://doi.org/10.1108/JEIM-02-2014-0013.

[3] M. Cocosila and N. Archer, "Adoption of mobile ICT for health promotion: an empirical investigation," Electron Markets, vol. 20, pp. 241-250, 2010, doi: https://doi.org/10.1007/s12525-010-0042-y.

[4] J. Alipour, A. Karimi, Saeid Ebrahimi, Fatemeh Ansari, and Yousef Mehdipour, "Success or failure of hospital information systems of public hospitals affiliated with Zahedan University of Medical Sciences: A cross sectional study in the Southeast of Iran,' International Journal of Medical Informatics, vol. 108, pp. 49-54, 2017, doi: 10.1016/j.ijmedinf.2017.10.005

[5] V. P. Aggelidis and P. D. Chatzoglou, "Hospital information systems: Measuring end user computing satisfaction (EUCS)," Journal of Biomedical Informatics, vol. 45, no. 3, pp. 566-579, 2012, doi: https://doi.org/10.1016/j.jbi.2012.02.009.

[6] F. Karimi, D. C. C. Poo, and Yung Ming Tan, "Clinical information systems end user satisfaction: The expectations and needs congruencies effects," Journal of Biomedical Informatics, vol. 53 , pp. 342-354, 2015, doi: https://doi.org/10.1016/j.jbi.2014.12.008.

[7] A. Alias, E.M.A. Zawawi, and Khalid Yusof, "Determining Critical Success Factors of Project Management Practice: A conceptual framework," Proceeding Social and Behavioral Sciences, 2014, pp. 61-69.

[8] F. Sadoughi, K. H. Kimiafar, M. Ahmadi, M. T. Shakeri, "Determining of Factors Influencing the Success and Failure of Hospital Information System and Their Evaluation Methods: A Systematic Review," Iran Red Crescent Med J, vol. 15, no. 12, 2013.

[9] N. I. Ismail, Nor Hazana Abdullah, and Alina Shamsuddin, "Adoption of Hospital Information System (HIS) in Malaysian Public Hospitals," Proceeding Social and Behavioral Sciences, 2015, pp. 336-343.

[10] J. F. Cohen, E. Coleman, and Matheri J. Kangethe, "An importance-performance analysis of hospital information systemattributes: A nurses' perspective," International Journal of Medical Informatics, vol. 86, pp. 82-90, 2015, doi: https://doi.org/10.1016/j.ijmedinf.2015.10.010.

[11] (2016) Sevima website. [Online]. Tersedia: http://sevima.com/?portofolio=rumah-sakit-cipto-mangunkusumo 
[12] M. L. Drury-Grogan, "Performance on agile teams: Relating iteration objectives and critical decisions to project management success factors," Information and Software Technology, vol. 56, no. 5, pp. 506-515, 2014, doi: https://doi.org/10.1016/j.infsof.2013.11.003.

[13] Y. Lindsjorn, Dag I.K Sjoberg, Torgeir Dingsoyr, Gunnar R. Bergersen, Tore, and Dyba, "Teamwork Quality and Project Success in Software Development: A Survey of Agile Development Teams," The Journal of Systems \& Software, vol. 122, pp. 274-286, 2016, doi: https://doi.org/10.1016/j.jss.2016.09.028.

[14] J. J. Fowler and P. Horan, "Are Information Systems' Success and Failure Factors Related? An Exploratory Study," Journal of Organizational and End User Computing, vol. 19, no. 2, pp. 1-22, 2008.

[15] Delone and McLean, "Information Systems Success: The Quest for the Dependent Variable," Journal of Management Information Systems, vol. 3, no. 4, pp. 60-95, 1992, doi: 10.1287/isre.3.1.60.

[16] M. Mahdavian, H. Nazarian, M. Mahdavian, and N. Wattanapongsakorn, "An Investigation of the Success of Hospital Information Systems Implementation: A Case Study," International
Computer Science and Engineering Conference, 2014, pp. 329-333, doi: 10.1109/ICSEC.2014.6978217.

[17] R. Atkinson, "Project management: cost, time and quality, two best guesses and a phenomenon, its time to accept other success criteria," International Journal of Project Management, vol. 17, no 6, pp. 337-342, 1999, doi: https://doi.org/10.1016/S02637863(98)00069-6.

[18] Davies Cooke, "The 'real' success factors on projects," International Journal of Project Management, vol. 20, no. 3, pp. 185-190, 2002.

[19] T. Chow and D.-B. Cao, "A survey study of critical success factors in agile software projects," Journal of Systems and Software, vol. 8, no. 6, pp. 961-971, 2008, doi https://doi.org/10.1016/j.jss.2007.08.020.

[20] J. W. Creswell, Qualitative Inquiry and Research Design: Choosing Among Five Traditions, 2nd ed., London: SAGE Publications, 1998.

[21] R. K. Yin, Case Study Research Design and Methods, 2nd ed., Thousand Oaks, CA: SAGE Publications, 1989. 